cell catalysts, hindering the access of lactic acid to these catalysts and lowering the effective concentration of lactic acid available for oxidation. Hence the supply of energy is diminished; this produces a decrease in functional activity of the nervous centres in question and narcosis may ensue. It is clear from experiments-although much has yet to be done-that any mechanism resulting in deficient carbohydrate or lactic acid oxidation in the nervous system may well play a part in causing disorders of the functional activity of the nervous system.

The interesting question of the possibility of certain psychotic disorders having their origin in a state equivalent to oxygen deficiency at certain parts of the nervous system is thus raised. Evidence in favour of this possibility would be forthcoming if it could be shown that the body itself can produce substances which behave in a manner similar to narcotics. This seems to have been accomplished by Quastel and other investigators at Cardiff. They have found that certain substances, mainly breakdown products of tyrosine and tryptophane, have precisely similar effects to those of the narcotics on the oxidation of glucose or of lactic acid in the brain at equivalent concentrations. Mescaline has a similar effect. Most of the substances in question-tyramine, indole, and so on-are normally detoxicated in the body (chiefly in the liver), so that not more than traces can normally circulate in a healthy individual.

A disturbance in hepatic functions, however, makes it not difficult to visualise the presence in the blood of more than ordinary amounts of these toxic substances, and their circulation over a long period would create a condition in the nervous system the psychological effects of which would be expected to resemble those found in anoxæmia or light narcosis. Experiment has yet to show such a disturbance in detoxicating processes among certain psychotic types and attention is being focused on this problem.

Prolonged narcosis as a therapeutic method, which seems to be satisfactory in certain cases in that it brings about an improvement in the mental condition, has been used in recent years. Many, however, have abandoned it because of the production of toxic symptoms from the administration of the drug, which necessitated the cessation of this method of treatment before recovery was assured. A modified treatment of giving the patient a dose of glucose and an injection of insulin at the same time as the administration of the drug has proved very successful. Ketonuria and other serious complications cleared up and the narcosis treatment became practically safe.

\title{
Constitution of the Alloys of Iron and Manganese
}

$\mathrm{T}$ $\mathrm{HE}$ latest contribution to the really remarkable work on the alloys of iron which has been carried out now for many years at the National read at the meeting of the Iron and Steel Institute in September.

Fundamental work of this category demands as a

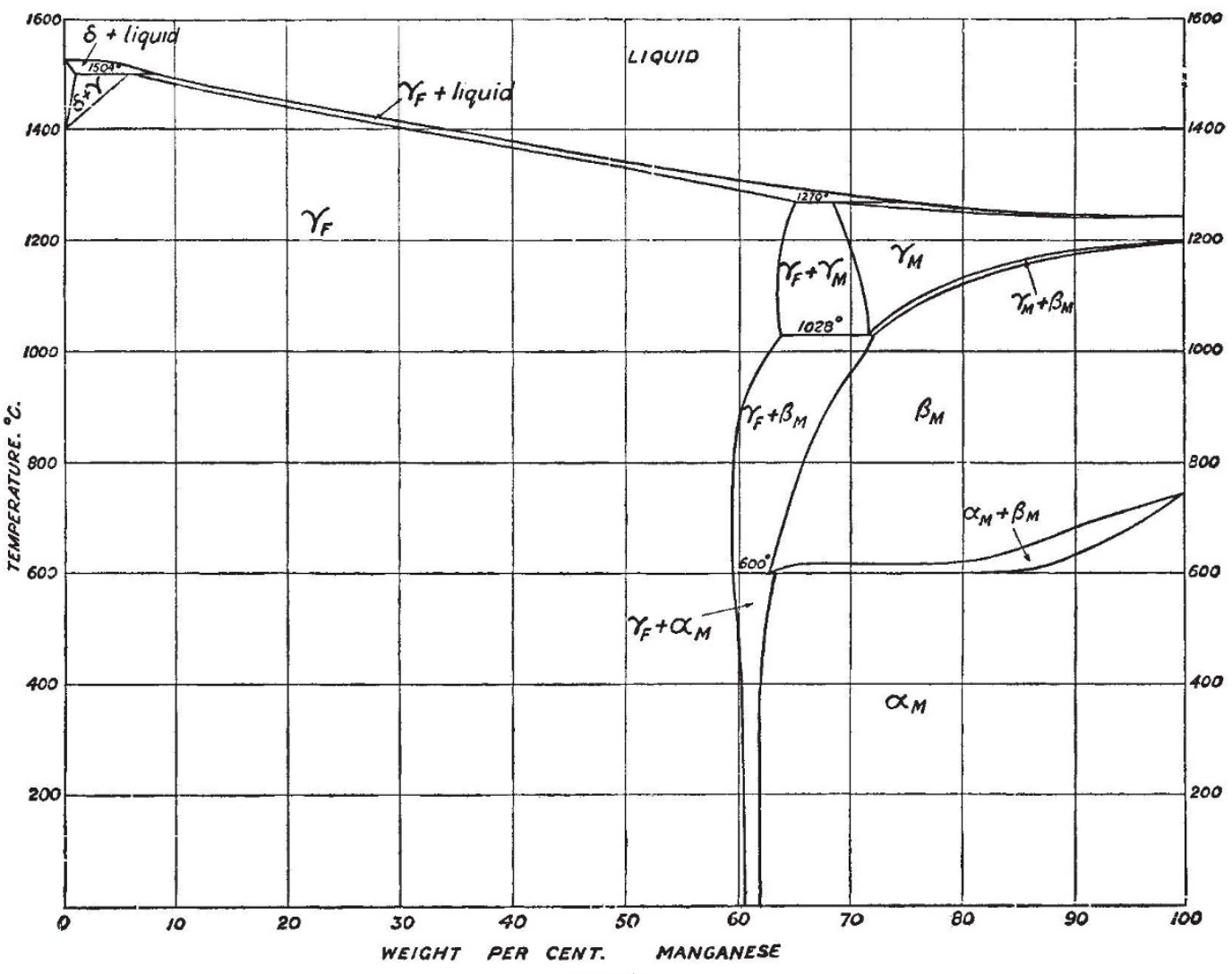

FIG. 1.

Physical Laboratory is a paper by Dr. M. L. V. preliminary the preparation of the elements themGayler on the manganese-iron alloys, which was $/$ selves in a state of high purity. The iron employed 
was prepared electrolytically, treated in hydrogen at a temperature of $900^{\circ}-1,000^{\circ} \mathrm{C}$. to remove oxygen, and then melted into ingot form in an induction furnace under hydrogen, being finally cooled in vacuo. The manganese was distilled from the thermit product. The metals were then remelted in magnesia crucibles in an electric induction furnace, being allowed to solidify three times with intermediate remeltings prior to the final solidification. To give an idea of the degree of purity of the final alloy the following composition of one with around 50 per cent of manganese may be cited : carbon, 0.007 ; silicon, 0.023 ; sulphur, 0.014 ; phosphorus, 0.0013 ; manganese, $47 \cdot 88$ per cent.

It is pointed out that the refractory materials available for the crucibles, thermo-couple sheaths, etc., has a profound effect upon the results in such work, and the analysis given above shows the extent to which the absorption of impurities by the metals from the refractories with which they have been in contact has been overcome. To all workers with metals at very high temperatures the observations made upon the refactory materials which were tried will be of the greatest value. The remainder of the experimental technique attains that high standard for which the work at the National Physical Laboratory in this field is famed.

The diagram proposed is shown in Fig. 1, reproduced from Dr. Gayler's paper by courtesy of the council of the Iron and Steel Institute, which does not, however, contain data concerning the constitution of the iron-rich alloys in the solid state. This part of the problem still requires further work. It will be seen that the $\delta$ transformation, which occurs at $1,504^{\circ} \mathrm{C}$., extends from 1 to 8 per cent of manganese, after which $\gamma$-iron separates directly from the melt until the manganese content attains about 74 per cent. Between 65 and 74 per cent of manganese a peritectic reaction occurs between this $\gamma$-iron and the manganese-rich liquid at a temperature of $1,270^{\circ} \mathrm{C}$. to form a phase containing about 68 per cent of manganese. With higher manganese contents, the solid solution containing the $\gamma$-manganese phase separates directly from the melt.

At the manganese end of the diagram the changes in the solid state have been determined with great care. At a temperature of $1,028^{\circ} \mathrm{C}$. with a manganese content of from 64 to 72 per cent, the $\gamma$-manganese phase separates into $\gamma$-iron and a $\beta$-manganese solid solution. At $600^{\circ} \mathrm{C}$. a further transformation of the $\beta$-manganese takes place with the formation of $\gamma$-iron and the $\alpha$-solution of the manganese between 59 and 63 per cent of that element.

F. C. T.

\section{University and Educational Intelligence}

IN "The Art of Teaching by Radio", Bulletin No. 4 of 1933, the United States Office of Education has published a report intended to serve as a manual for those who aspire to broadcast the seed of learning. That their number in the United States is large may be inferred from the fact that specialists in education by radio are employed on the staff of the Office of Education. It is indeed the senior member of this specialist staff who is responsible for the report, which is based on a very elaborate investigation conducted with the help of some hundreds of transmitting stations, the Association of College and University Stations, the National Association of Broadcasters, and other representatives of radio and educational interests. It expresses a consensus of opinion among experts as to the best technique for preparing, advertising and transmitting educational programmes and as to preparing the ground for their reception by providing supplementary aids for listeners. Appended to it is a bibliography comprising ninety-one items, about a third of which have a European (chiefly British) origin. It is a convenient summary, well adapted to serve its purpose. Special sections deal with music, the drama, debates and dialogues.

ScHool administrators and teachers in the United States are exhorted by the Commissioner of Education in the September issue of School Life to co-operate in President Roosevelt's great national recovery scheme, so as to make school work a fitting preparation for life in the new world. This formidable task is aggra. vated by the fact that the N.R.A. code prohibition of employment of children less than sixteen years of age in industry and commerce automatically increases the school population by about 100,000 . A more serious difficulty than the finding of accommodation for these additional pupils is the organisation of curricula suitable to the requirements of pupils of types for which the schools have not been accustomed to provide, and especially of those who have already been employed in paid work and are now obliged to go back to school. This acute need for programmes of schoolwork appropriate to the requirements of 'working class' adolescents comes at a time when retrenchment policies have eliminated many of the courses in music, home economics, vocational guidance and the arts and crafts, and provisions for exceptional children. The problem is discussed in an article entitled "The Children's Code" by one of the specialists in the Office of Education.

From the Universities Bureau of the British Empire we have received a copy of a report of its executive council for 1932-33. The list of members comprises the nineteen universities of the British Isles, eleven Canadian universities (including all the larger universities except those of British Columbia, Manitoba and Montreal), the three principal Australian and the four South African universities, those of New Zealand, Malta and Hong-Kong and nine of the Indian universities. Among the services rendered by the Bureau are the production of the "Year-book of the Universities of the Empire", the secretarial work of the Committee of Vice-Chancellors and Principals, the administration of certain trusts, including the Carnegie Corporation grant for enabling selected members of staffs of overseas universities to visit Great Britain, and assistance to overseas universities in the selection of candidates for academic posts. Last year, the Bureau made arrangements for a visit of eight German professors (of theology, chemistry, medicine, English, ship- and airshipbuilding, physics and architecture) to British universities. No conference of the home universities was held, but regional universities' conferences were held in Australia (at Sydney in August 1932), South Africa (Vice-Chancellors' Committee of South African Universities, at Johannesburg in July 1932 and at Cape Town in February and June 1933) and India (Inter-University Board, at Hyderabad in February 1933). The report contains lists of subjects discussed at these conferences and at the quarterly meetings of the home universities' Committee of Vice-Chancellors and Principals. Appended to the report are fully annotated accounts for the year. 